University of Wollongong

Research Online

Faculty of Engineering and Information

Faculty of Engineering and Information

Sciences - Papers: Part B

Sciences

2020

Effect of the Second-Phase Particle Precipitation on the Recrystallization

Texture of High-Strength and Fine-Grain Interstitial-Free Steel

H Zhang

R Chen

C Wang

Y Li

H Jia

See next page for additional authors

Follow this and additional works at: https://ro.uow.edu.au/eispapers1

Part of the Engineering Commons, and the Science and Technology Studies Commons

Research Online is the open access institutional repository for the University of Wollongong. For further information contact the UOW Library: research-pubs@uow.edu.au 


\title{
Effect of the Second-Phase Particle Precipitation on the Recrystallization Texture of High-Strength and Fine-Grain Interstitial-Free Steel
}

\author{
Abstract \\ (C) 2020, Springer Science+Business Media, LLC, part of Springer Nature. The effect of the second-phase \\ particle precipitation on the recrystallization texture of high-strength and fine-grain interstitial-free steel \\ was studied. It is shown experimentally that the sizes of second-phase particles increase and their \\ number decreases with holding time and annealing temperature. The texture is mainly influenced by the \\ size, number, and distribution of the particles. Finely dispersed second-phase particles are strongly \\ pinned on the grain boundaries, which significantly hinders the development of $\{111\}$ surface textures. It \\ the pinning force on the grain boundary decreases, the $\{111)$ surface texture improves due to the \\ aggregation and growth of second-phase particles with holding time. The strength of the $Y$-phase $(\{111\}$ \\ texture) grows and reaches maximum (annealing temperature $850^{\circ} \mathrm{C}$ ), finally declines with annealing \\ temperature. Precipitated particles of $40-60 \mathrm{~nm}$ favor the development of the $\{111\}$ texture component. \\ Disciplines \\ Engineering | Science and Technology Studies

\section{Publication Details} \\ Zhang, H., Chen, R., Wang, C., Li, Y., Jia, H. \& Jiang, Z. (2020). Effect of the Second-Phase Particle \\ Precipitation on the Recrystallization Texture of High-Strength and Fine-Grain Interstitial-Free Steel. \\ Strength of Materials, 52 40-50.

\section{Authors} \\ H Zhang, R Chen, C Wang, Y Li, H Jia, and Zhengyi Jiang
}




\title{
Effect of the Second-Phase Particle Precipitation on the Recrystallization Texture of High-Strength and Fine-Grain Interstitial-Free Steel
}

\author{
H. M. Zhang, ${ }^{\text {a,b,1 }}$ R. Chen, ${ }^{a}$ C. S. Wang, ${ }^{b}$ Y. Li, ${ }^{b}$ H. B. Jia, ${ }^{a}$ and Z. Y. Jiang ${ }^{a, c}$
}

The effect of the second-phase particle precipitation on the recrystallization texture of high-strength and fine-grain interstitial-free steel was studied. It is shown experimentally that the sizes of second-phase particles increase and their number decreases with annealing time and temperature. The texture is mainly influenced by the size, number, and distribution of the particles. Fine an dispersed second-phase particles are strongly pinned on the grain boundaries, which significantly hinders the development of $\{111\}$ surface textures. It the pinning force on the grain boundary decreases, the (111) surface texture improves due to the aggregation and growth of second-phase particles with annealing time. The strength of the $\gamma$-phase $(\{111\}<112>$ texture) grows and reaches maximum (annealing temperature $850^{\circ} \mathrm{C}$ ), finally declines with annealing temperature. Precipitated particles of 40-60 $\mathrm{nm}$ favor the development of the $\{111\}$ texture component.

Keywords: second-phase particles, precipitation, recrystallization texture, grain boundary, high-strength and fine-grain interstitial-free steel.

Introduction. With the rapid development of the automobile manufacturing industry, energy saving and emission reducing become more and more important. How to reduce the weight of the automobile body under the condition of safety become a very important issue [1-4].

It is well known that interstitial-free steel (IF steel) is a kind of deep-drawing steel which is widely used in the manufacture of automobile body panels because of its good drawability, surface quality, and recycling [5-7]. The drawability of IF steels, usually quantified in terms of the Lankford value $r$, is strongly dependent on recrystallization texture. IF deep drawing steel has good drawability because of its strong recrystallization texture $\gamma$ fiber $(<111>/ / \mathrm{ND})$ and weaker $\alpha$ fiber texture $(<110>/ / \mathrm{ND})$. Plastic strain ratio ( $r$ value) is the main index influencing IF steel's forming performance, and high $r$ value indicates that the steel plate has a good forming performance [8-10].

A new IF steel added the $\mathrm{Nb}$ element was developed in this study and the strengthening of dispersion and grain refinement can be achieved by $\mathrm{Nb}(\mathrm{C}, \mathrm{N})$ precipitates. Excellent deep drawability (high $r$-value) can be obtained by fixing $\mathrm{C}$ and $\mathrm{N}$, and high strength steel can be obtained by grain refinement of steel [11-15].

The recrystallization texture of IF steel is influenced by many factors, such as the chemical composition, steelmaking, hot rolling, cold rolling, and annealing process. Many researchers had different views about the effect of the second-phase particles on recrystallization texture. Some researchers believed that the formation of large and homogeneous second-phase particles can improve the recrystallization textures obtained during the process of cold rolling and recrystallization annealing. Other researchers, however, claimed that the presence of second-phase particles during cold rolling have no effect on the recrystallization textures [16-18].

In recent years, the effect of the precipitation behavior of the second-phase particles on recrystallization texture was studied. Wang et al. [19] found that the second-phase particles of TiS and $\operatorname{Ti}(\mathrm{C}, \mathrm{N})$ gather and grow during the process of hot rolling, as well as the fine FeTiP particles precipitated at the same time. Zhao et al. [20] studied the precipitation behavior of the second-phase particles in Ti-bearing steel and found that when the amount of $\mathrm{Ti}$ added to the steel is very small, the interstitial atom $\mathrm{N}$ will combine with Al to form the second-phase particles. Song et al. [21] had discovered the evolution of 
microstructure and texture of $0.2 \% \mathrm{C}-\mathrm{Mn}$ steel during large warm deformation and subsequent annealing. It was reported that the removal of $\mathrm{C}$ from the solid solution by the precipitates can benefit to $\{111\}$ texture in IF steel $[22,23]$. Ghosh et al. $[24,25]$ presented an overview of the different types of precipitates in high strength interstitial free steels and reported that the formability decreases with the increase of the volume fraction of FeTiP precipitation.

The effects of the second-phase particles precipitation on mechanical properties and the recrystallization texture of IF steel have been studied in recent years, however, there are very little research into the effect of second-phase particles precipitation on the formation mechanism of the recrystallization texture until now.

The second-phase particle precipitation and its effect on the recrystallization textures of the fine grain and high-strength IF steel were studied in this paper. The morphology and composition of the second-phase particles and the intensity change of the $\gamma$-fiber texture $(\{111\}<112>)$ under different annealing processes were also investigated.

\section{Experimental Materials and Methods.}

1.1. Experimental Materials. The experimental steel was melted in the laboratory of University of Science and Technology Liaoning. $\mathrm{Nb}$ was added to the experimental steel in order to form fine and dispersed second-phase precipitates. The chemical compositions of experimental steel are shown in Table 1.

Table 1

Chemical Compositions of Experimental Steel (wt.\%)

\begin{tabular}{|c|c|c|c|c|c|c|c||}
\hline Element & $\mathrm{C}$ & $\mathrm{Si}$ & $\mathrm{Mn}$ & $\mathrm{P}$ & $\mathrm{S}$ & $\mathrm{Nb}$ & $\mathrm{B}$ \\
\hline Content & $0.0043 \pm 0.002$ & $0.267 \pm 0.04$ & $1.88 \pm 0.04$ & 0.062 & 0.0063 & $0.097 \pm 0.03$ & 0.0007 \\
\hline
\end{tabular}

\subsection{Experimental Methods.}

1.2.1. Experimental Procedure. Sample dimension experimental steel was $200 \times 100 \times 1 \mathrm{~mm}(L \times W \times H)$. Cold rolling was conducted by the cold rolling mill in the State Key Laboratory of Rolling and Automation, Northeastern University. Cold rolling reduction was $85 \%$. The annealing experiments were carried out in the annealing furnace at the University of Science and Technology of Liaoning. Experimental steel were heated to 830,850 , and $870^{\circ} \mathrm{C}$, respectively, and annealing time were 5, 10, 20, 40, and $60 \mathrm{~min}$, respectively, under an annealing temperature of $850^{\circ} \mathrm{C}$ after cold rolling.

The primary TEM samples were taken based on the metallographic experiment, and the surface of samples eroded with $4 \%$ nitric acid alcohol solution was treated by sprayed carbon, and then the samples with carbon membrane were put into a $4 \%$ nitric acid alcohol solution until the carbon membrane separated from the samples. The carbon membranes were taken out by the copper net and put on the filter paper. Finally, TEM samples were obtained.

Annealing process of experimental steel is shown in Table 2.

Table 2

Annealing Process of Experimental Steel

\begin{tabular}{||c|c|c|c|c||}
\hline \hline Number & $\begin{array}{c}\text { Heating rate, } \\
{ }^{\circ} \mathrm{C} / \mathrm{s}\end{array}$ & $\begin{array}{c}\text { Temperature, } \\
{ }^{\circ} \mathrm{C}\end{array}$ & $\begin{array}{c}\text { Annealing time, } \\
\mathrm{min}\end{array}$ & Cooling type \\
\hline 1 & 5 & 830 & 40 & \multirow{2}{*}{ Air-cooled } \\
\hline 2 & 5 & 850 & $5,10,20,40,60$ & \\
\hline 3 & 5 & 870 & 40 & \\
\hline
\end{tabular}


1.2.2. Microstructure and Texture (Grain Orientation). The microstructure of the samples were observed by ZEISS optical microscope. The morphology, size, quantity, and components of the second-phase particles were obtained by extraction complex experiment using JEOL-2100 TEM and EDX. Microzone Orientation Imaging analysis were performed by the analytical testing technique of JSM6480LV - SEM + PEGASUS2040 - EDS + EBSD. The OIM5.31 (Orientation Imaging Microscopy) software was used for texture analysis. The phase of experimental steel was obtained by XRD.

\section{Results and Discussion.}

\subsection{Experimental Results under Different Annealing Temperatures.}

2.1.1. The Effect of Second-Phase Particles on the Texture of Experimental Steel under Different Annealing Temperatures. The morphology and EDX of the second-phase particles and orientation density function (ODF) figures under different annealing temperatures (annealing time is $40 \mathrm{~min}$ ) are shown in Fig. 1.

It can be seen that when the annealing temperature is at $830^{\circ} \mathrm{C}$, a large number of fine second-phase particles are distributed uniformly in the matrix as shown in the left side of Fig. 1a. The size of the large particle with the irregular rectangular shape confirmed $\mathrm{NbCN}$ by EDX as shown in the right side of Fig. 1a is about $50 \mathrm{~nm}$ (circled with red line), and the sizes of small particles with the round or oval shape are about $20 \mathrm{~nm}$. When the annealing temperature is at $850^{\circ} \mathrm{C}$, the number of precipitation particles decrease and the particles size increases. It can be seen that the small particles gather together. As a result, the number of the particles decrease and the size of second-phase particles increases with the increase of the annealing temperature. At the same time, the average gain size is about $50 \mathrm{~nm}$ with round shape as shown in the left side of Fig. 1b. When the annealing temperature is at $870^{\circ} \mathrm{C}$, the rectangular shape particle (circled with red line) is confirmed as $\mathrm{Nb}(\mathrm{CN})$ by EDX as shown in the right side of Fig. 1c.

2.1.2. Two Phase Particle Parameters and ODF Data at Different Annealing Temperatures. The size of two-phase particles was calculated using Photoshop and IPP. SEM+EBSD was used for texture analysis, and Channel 7 software was used for ODF analysis. ODF data in different annealing temperatures were obtained by EBSD. It can be seen that the intensity value of the strongest point (close to $\{111\}<112>$ ) of $\gamma$ fiber texture in experimental steel changes greatly with the increase of annealing temperature. The values are 10.0, 14.6, and 13.1, respectively, as shown in the right side of Fig. 2 and Table 3. When the annealing temperature is at $830^{\circ} \mathrm{C}$, a large number of $\mathrm{NbC}$ particles with the size of 10 to $30 \mathrm{~nm}$ are distributed in the matrix. The precipitated particles are pinning on the grain boundary. As a result, the grain growth is hindered. Consequently, the recrystallization texture cannot form sufficiently and the development of the $\{111\}$ texture component is significantly restrained, and the texture intensity value is only 10 . With the increase of the annealing temperature from 830 to $850^{\circ} \mathrm{C}$, the precipitated second-phase particles in the steel become large and uniform, with an average size of $60 \mathrm{~nm}$. The pinning force of sparse and coarse second-phase particles on grain growth during recrystallization annealing process becomes weaker, and the grain recrystallization is completed due to little impact of the sparse and coarse second-phases on ferrite grain growth. The growth rate of $\{111\}$ grain orientation is significantly higher than random grain orientation and others grain orientation after annealing as shown in Table 3, subsequently, the $\{111\}$ orientation grains can grow up completely. The intensity of the $\{111\}$ texture component increases gradually and reach to the maximum value of 14.6 at the annealing temperature of $850^{\circ} \mathrm{C}$. With the decrease of the amount of large particles and the particles at $870^{\circ} \mathrm{C}$ the annealing temperature, the $\{111\}$ texture component is less than that of at $850^{\circ} \mathrm{C}$, the annealing temperature, as shown in Fig. 1 and Table 3. Hence, it can be seen that the size and the number of second-phase particles have a great effect on the development of texture. The effects of the second-phase particles on the recrystallization texture of the high strength IF steel are mainly determined by the size, the number and the distribution of the particles as shown in Fig. 1. 

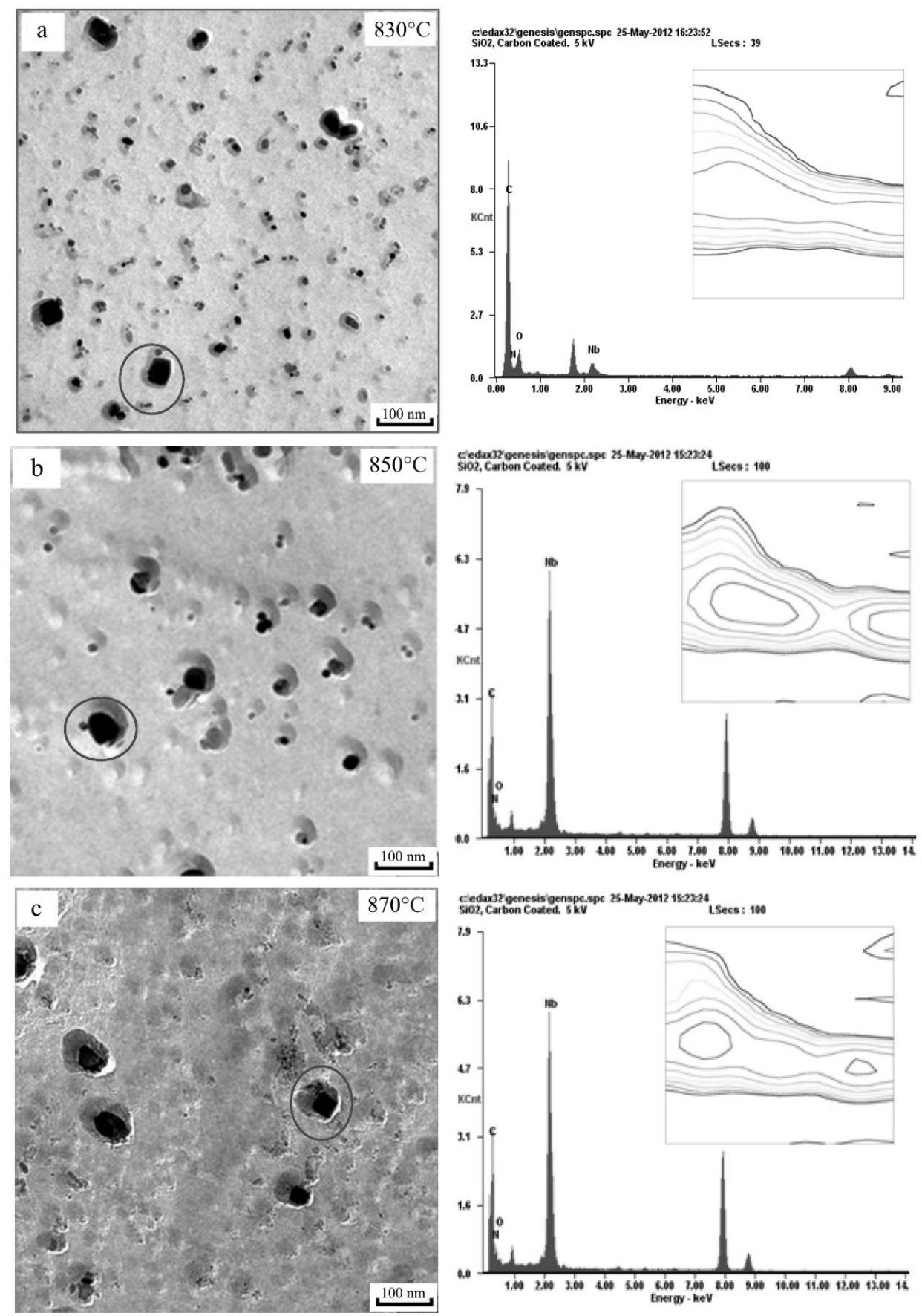

Fig. 1. The morphology and EDX of second-phase and ODF figures under different annealing temperatures (annealing time is $40 \mathrm{~min}$ ): 830 (a), 850 (b), and $870^{\circ} \mathrm{C} \mathrm{(c).}$

2.1.3. XRD Analysis of the Experimental Steel. The crystal structure and the phases formation of the the experimental steel surface at 830,850 , and $870^{\circ} \mathrm{C}$ annealing temperature for 40 min annealing time were investigated by the XRD analysis as shown in Fig. 2. It can be seen that the crystal structure and the phases of the experimental steel surface at 830 , 850 , and $870^{\circ} \mathrm{C}$ annealing temperature for 40 min annealing time are $\alpha$ (ferrite). 
Ta ble 3

Parameters of Second-Phase Particles and ODF Data in Different Annealing Temperatures

\begin{tabular}{||c|c|c|c|}
\hline \multirow{2}{*}{ Parameter } & \multicolumn{3}{|c|}{ Temperature $\left({ }^{\circ} \mathrm{C}\right)$} \\
\cline { 2 - 4 } & 830 & 850 & 870 \\
\hline ODF (max) & 10.0 & 14.6 & 13.1 \\
\hline Particles size $(\mathrm{nm})$ & 20 & 60 & 100 \\
\hline Volume fraction $(\%)$ & 0.12 & 0.08 & 0.04 \\
\hline Component & $\mathrm{NbC}$ & $\mathrm{Nb}(\mathrm{CN})$ & $\mathrm{Nb}(\mathrm{CN})$ \\
\hline
\end{tabular}

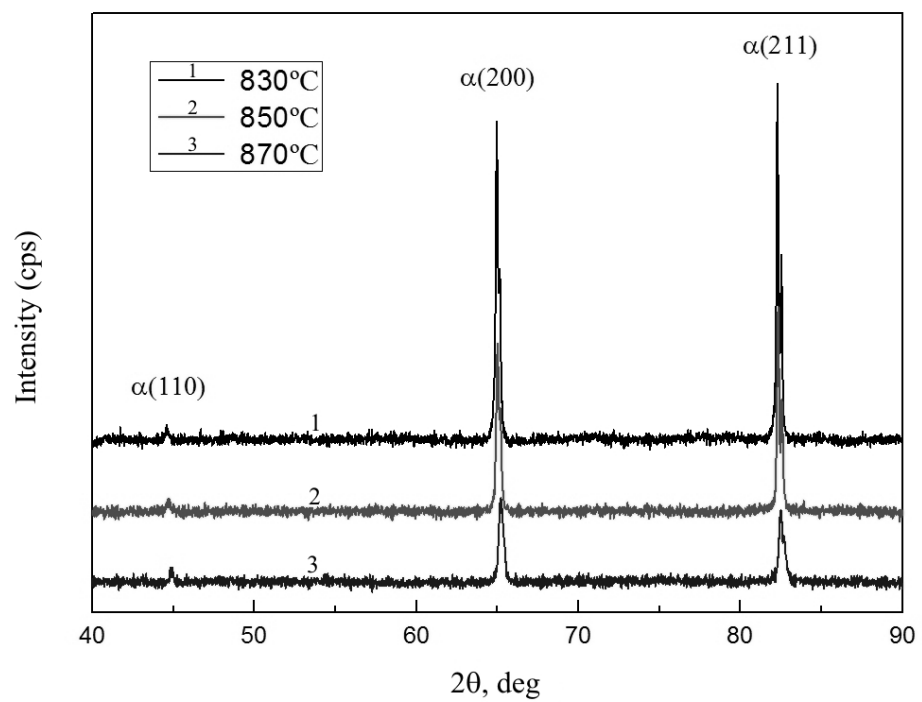

Fig. 2. XRD analysis on the surface of the experimental steel at 830,850 , and $870^{\circ} \mathrm{C}$ annealing temperature.

\subsection{Experimental Results under Different Annealing Times.}

2.2.1. The Microstructure of Experimental Steel under Different Annealing Times. Figure 3 shows the microstructure of the experimental steel at different annealing times. It can be found that the ferrite grains grew gradually with the increase of holding time. From 20 to $40 \mathrm{~min}$, the ferrite grain was fully recrystallized, and the ferrite grain arrangement was relatively regular.
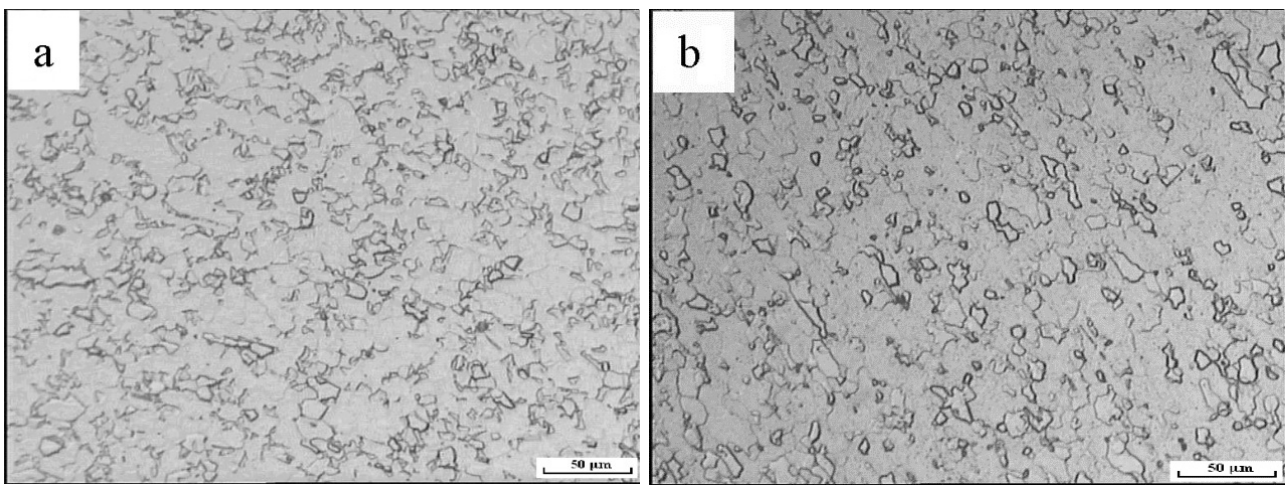

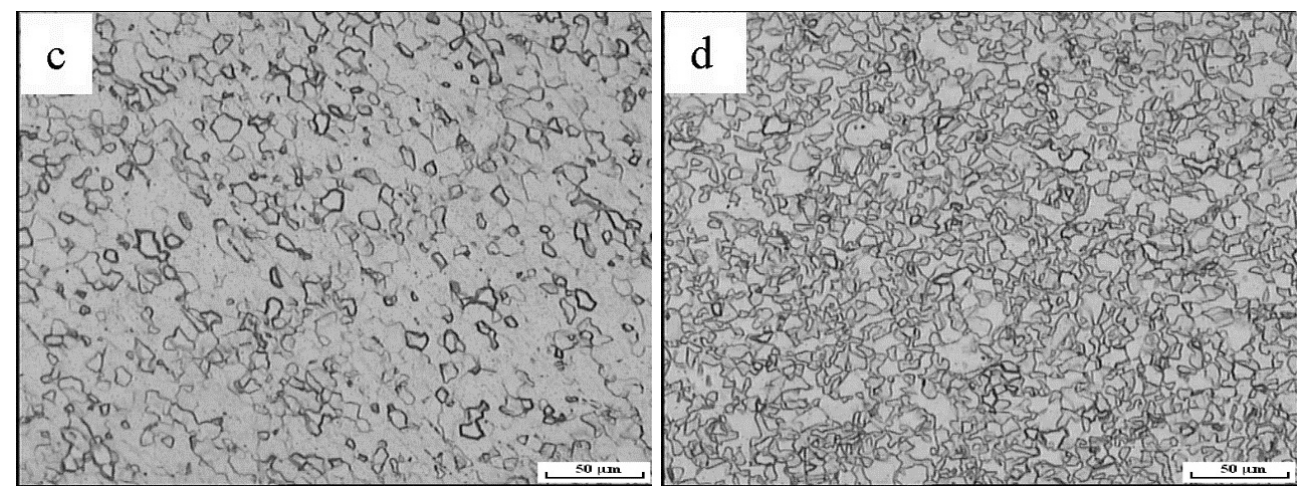

Fig. 3. Microstructure of experimental steel at $850^{\circ} \mathrm{C}$ under different annealing time: 5 (a), 10 (b), 20 (c), and $40 \min (d)$.

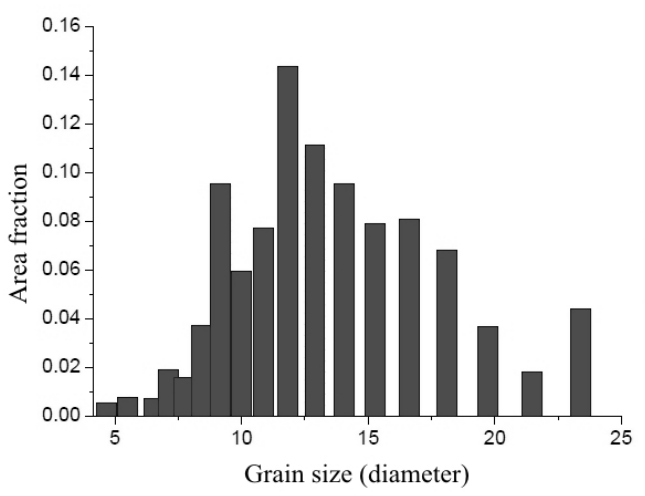

a

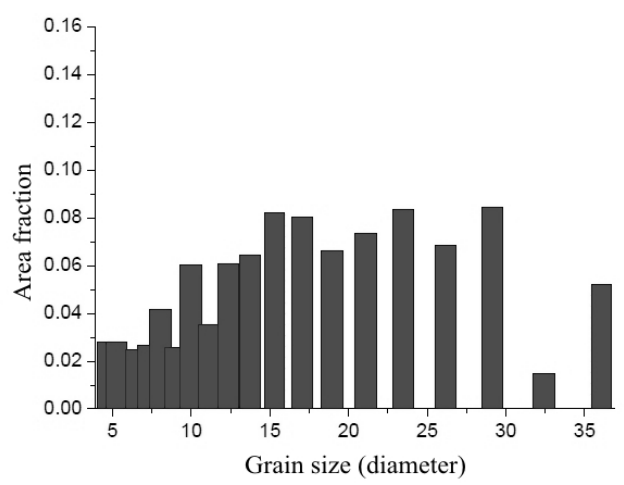

c

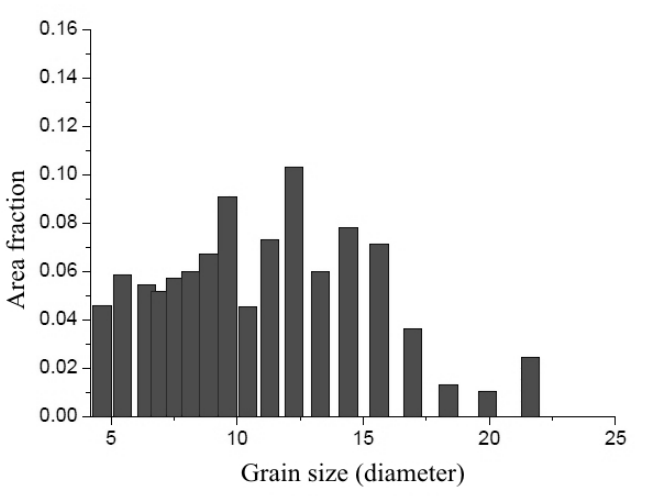

b

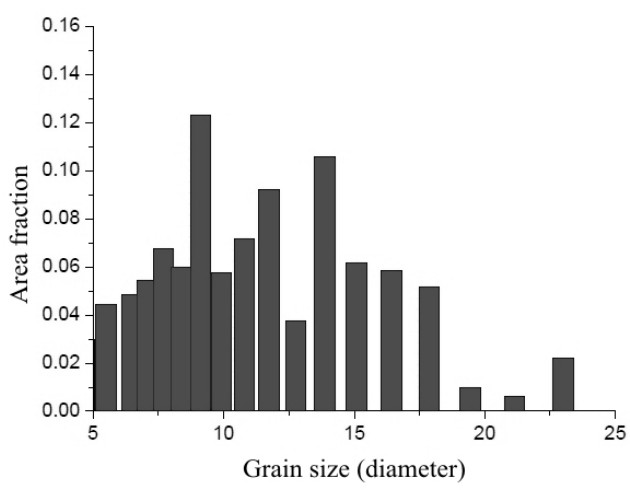

d

Fig. 4. The grain size chart of $1 / 2$ layer at $850^{\circ} \mathrm{C}$ under different annealing times: 5 (a) 10 (b), 20 (c), and $40 \mathrm{~min}(\mathrm{~d})$.

2.2.2. The Grain Size Distribution of Experimental Steel. The statistical distributions of grain size in the 1/2 layer of experimental steel at different annealing times were measured using EBSD, as shown in Fig. 4. It can be seen that the grain size of $1 / 2$ layer under different annealing times is mostly concentrated around $13 \mu \mathrm{m}$. The grain size increases with the increase of holding time. 
Mechanical Properties of Experimental Steel in Different Annealing Times

\begin{tabular}{|c|c|c|c|c|c||}
\hline $\begin{array}{c}\text { Holding time } \\
(\mathrm{min})\end{array}$ & $\begin{array}{c}\text { Tensile strength } \\
(\mathrm{MPa})\end{array}$ & $\begin{array}{c}\text { Yield strength } \\
(\mathrm{MPa})\end{array}$ & $\begin{array}{c}\text { Elongation } \\
(\%)\end{array}$ & $n$ & $r$ \\
\hline 5 & 456.0 & 261.4 & 34.1 & 0.23 & 2.03 \\
\hline 10 & 407.2 & 225.5 & 34.3 & 0.22 & 1.95 \\
\hline 20 & 431.4 & 242.0 & 28.0 & 0.21 & 1.88 \\
\hline 40 & 447.6 & 246.7 & 36.8 & 0.24 & 2.13 \\
\hline 60 & 453.2 & 282.4 & 34.1 & 0.23 & 1.91 \\
\hline
\end{tabular}

\subsubsection{Effect of Annealing Time on Mechanical Properties of Fine Grain High} Strength IF Steel. Mechanical properties of experimental steel can be measured by tensile test as shown in Table 4. With the increase of annealing time, the tensile strength and yield strength changed little. The elongation decreases at first and then rises, $n$ value (work hardening index) and $r$ value (plastic strain ratio) were both increase, and peak value appears at $40 \mathrm{~min}$ annealing holding time, and then falls again.

2.2.4. The Effect of Second-Phase Particles on the Texture of Experimental Steel under Different Annealing Times. The morphology, EDX of second-phase particles and texture at different annealing times are shown in Fig. 5. It is can be seen that the precipitated second-phase particles consist of some large and small particles. The sizes of large particles are from 40 to $100 \mathrm{~nm}$ and the sizes of small particles are from 10 to $40 \mathrm{~nm}$. When the annealing time is $20 \mathrm{~min}$, the size of the large precipitated particles reaches up to $80 \mathrm{~nm}$. The second-phase particle with the rectangular shape (circled with a red line) is confirmed as the carbonitride of $\mathrm{Nb}(\mathrm{NbCN})$ by EDX results as shown in the right side of Fig. 5a and its size is about $50 \mathrm{~nm}$. When the annealing time is between 20 to $40 \mathrm{~min}$, the small second-phase particles disappears completely and the amount of large particles decrease. The second-phase particle with the round shape (circled with a red line) is confirmed as the carbide of $\mathrm{Nb}(\mathrm{NbC})$ by EDX as shown in the right side of Fig. $5 \mathrm{~b}$ and its size is about $50 \mathrm{~nm}$. The second-phase particle with the irregular rectangle shape (circled with a red line) is confirmed as the carbonitride of $\mathrm{Nb}(\mathrm{NbCN})$ by EDX as shown in the right side of Fig. $5 \mathrm{c}$ and its size is about $100 \mathrm{~nm}$. The second-phase particles with the round or oval shape are mainly $\mathrm{NbC}$. The second-phase particles with square or irregular rectangular shape are mainly conformed as $\mathrm{Nb}(\mathrm{C}, \mathrm{N})$.

The ODF $\left(=45^{\circ}\right)$ in its half layer of the experimental steel under different annealing times at $850^{\circ} \mathrm{C}$ is shown in the right side of Fig. 5, and it is combined with the EDX results. It is shown that all the textures of in its half layer of the experimental steel under different annealing times are the strong $\gamma$-fiber texture $(\{111<u v w\rangle\}$ and the texture component is the same. The $\gamma$-fiber texture of experimental steel with 40 min annealing time is the strongest, and the maximum density value is 14.6 . The $\{111\}<110>$ texture turns to $\{111\}<112>$ texture as the annealing time is increased.

2.2.5. XRD Analysis of the Experimental Steel. The crystal structure and the phases formation in half layer of the experimental steel under 40 min annealing time was investigated by the XRD analysis as shown in Fig. 6 . It can be seen that the crystal structure and the phases in half layer of the experimental steel is $\alpha$ (ferrite).

2.2.6. Orientation Imaging Analysis of the Experimental Steel. The orientation imaging analysis of the experimental steel in its half layer at different annealing times is shown in Fig. 7. When the orientation difference is larger than $15^{\circ}$, the grain boundary is called the large angle grain boundary, and the $2-15^{\circ}$ orientation difference is called the small angle grain boundary. The different colors represent the different grain orientations. 

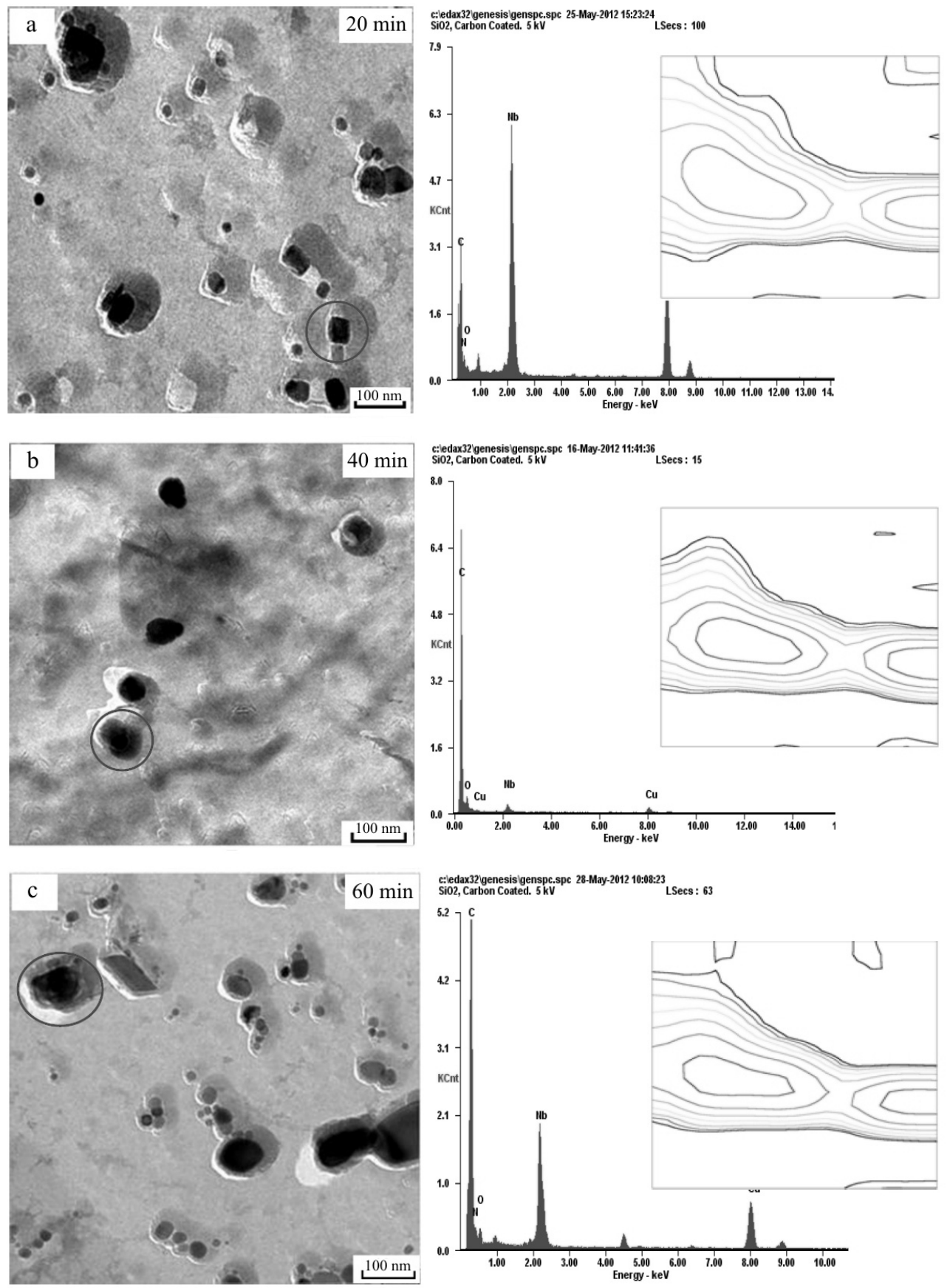

Fig. 5. Morphology and EDX of large second-phases and ODF figure under different annealing times: 20 (a), 40 (b), and $60 \min (\mathrm{c})$.

The blue color grain shows the crystal plane of $\{111\}$ parallel to the rolled surface, the red color grain represents the $\{001\}$ crystal plane parallel to the rolled surface, while the green color grain represents the $\{101\}$ crystal plane parallel to the rolled surface.

It can be seen that the ferrite grains appear recrystallized and the grain sizes become uniform and equiaxial. When the recrystallization is completed, their grain boundaries are 


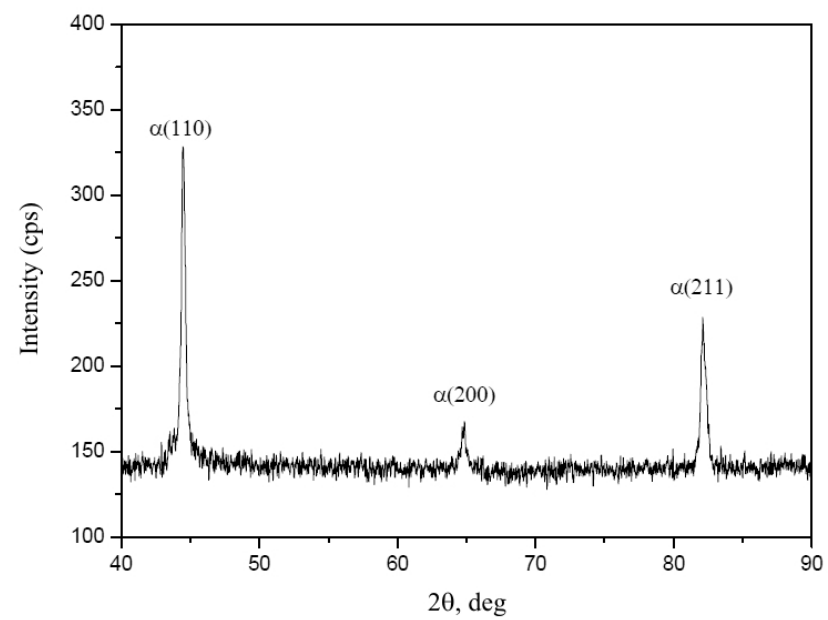

Fig. 6. XRD analysis of the experimental steel in half layer under 40 min annealing time.
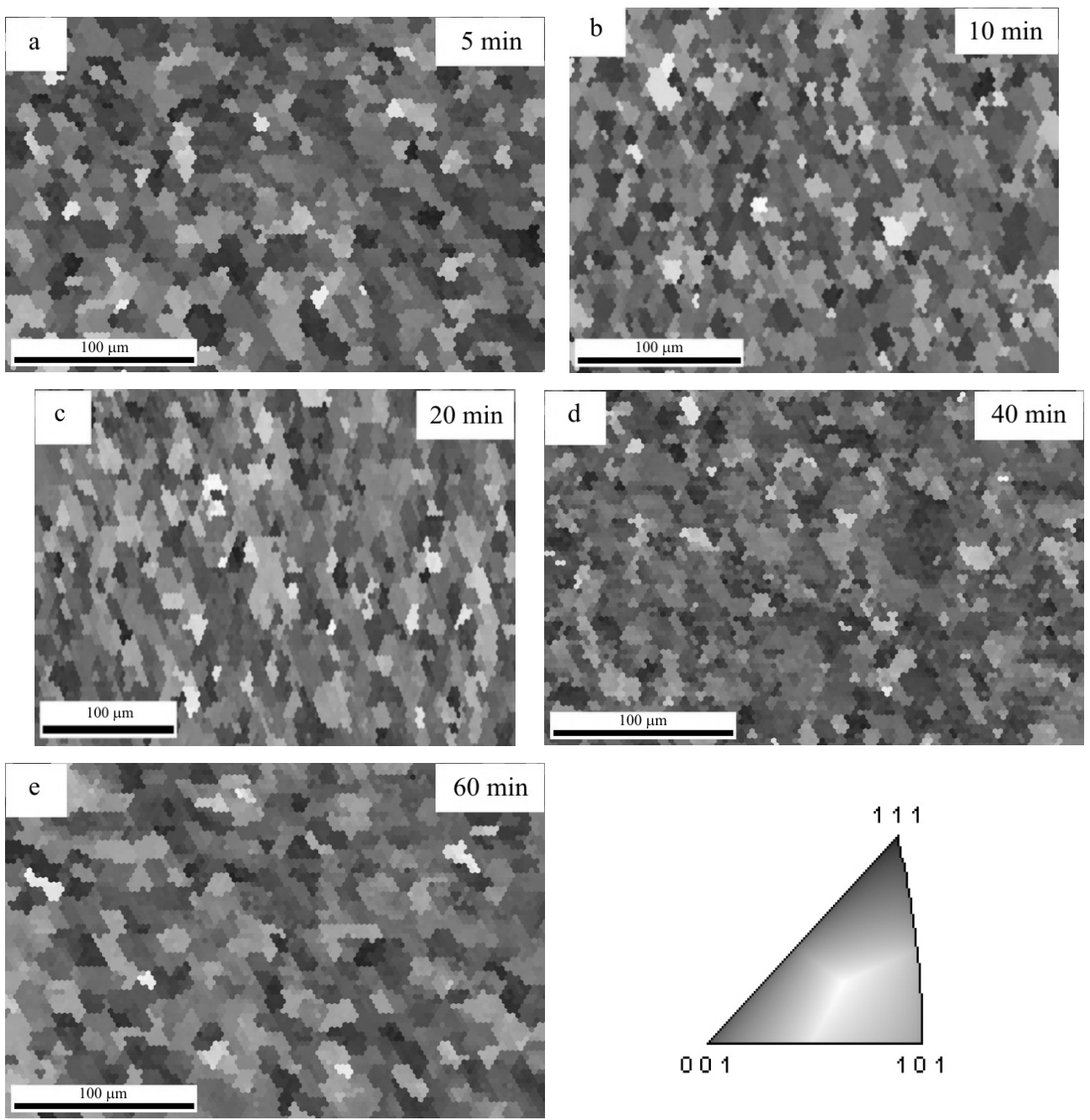

Fig. 7. Orientation imaging map of half layer under different annealing times. 

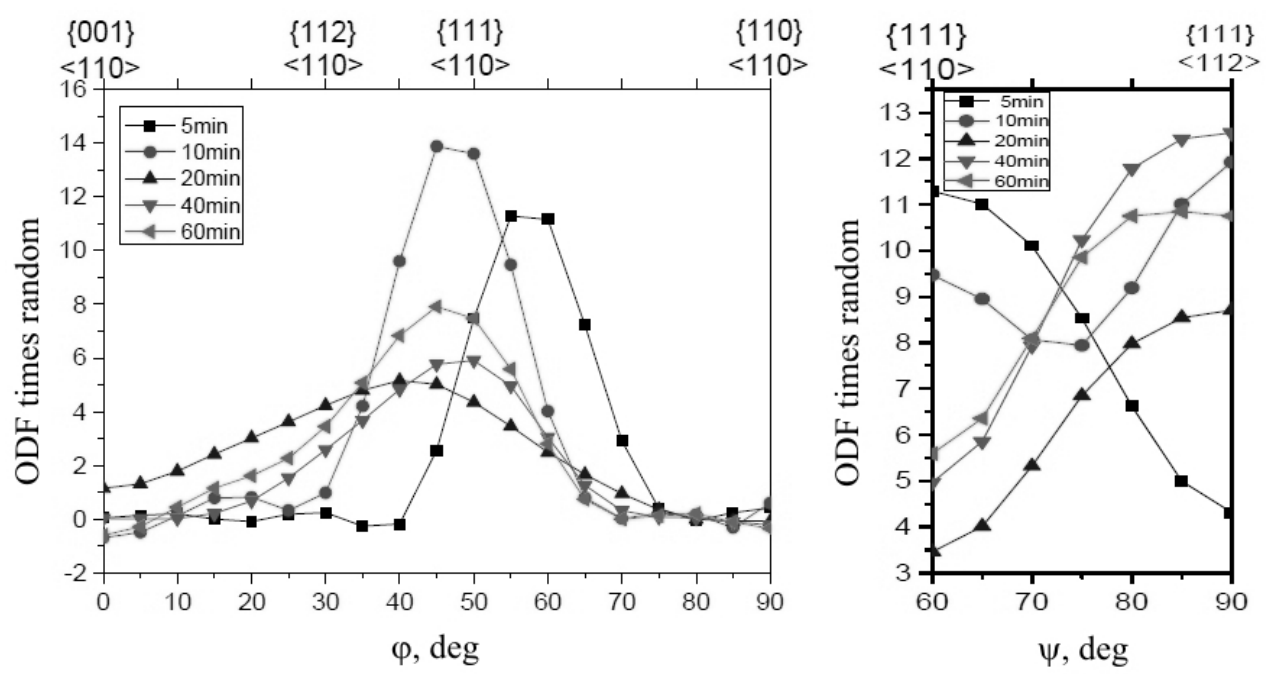

Fig. 8. The $\alpha$-orientation and $\gamma$-orientation line of half layer under different annealing times.

large angle grain boundaries and most of the grain orientations concentrate to the $<111>$ and $<112>$ direction. As a result, there are more blue color grains, which represent the $\{111\}$ orientation. The grains grow with the increase of annealing time. When the annealing time is $40 \mathrm{~min}$, the change of texture is not obvious and the microstructure is uniform.

2.2.7. The $\alpha$-Orientation and $\gamma$-Orientation Line of Half Layer under Different Annealing Times. The intensity changes of $\alpha$ and $\gamma$ fiber textures are shown in Fig. 8 under different annealing times. The left figure represents $\alpha$ fiber texture, and $\gamma$ fiber texture is shown in the right one. The intensity change of $\alpha$ fiber recrystallization texture from $\{001\}<110>$ to $\{112\}<110>$ is very large with the change of angle $\theta$ for experimental steel, especially for the texture of $\{001\}<110>$ and $\{111\}<110>$. The intensity of $\alpha$ fiber recrystallization textures improve when the annealing time extends from 5 to $10 \mathrm{~min}$. The peak of texture intensity changes from $\{118\}<110>$ to $\{111\}<110>$ and the density of $\{111\}<110>$ texture decreases with the increase of annealing time. The intensity of $\{111\}<110>$ decreases when the annealing time changes from 5 to $20 \mathrm{~min}$. The intensity changes of $\{111\}<110>$ are small when the annealing time extends from 20 to $60 \mathrm{~min}$. The intensity change of $\{111\}<112>$ reaches to the maximum value when the annealing time is $40 \mathrm{~min}$.

\section{Con clusions}

1. The sizes of second-phase particles become larger, and their numbers decrease with the increase of annealing temperature and annealing time.

2. The textures of experimental steel are mostly based on the $\{111\}$ and $\{112\}$ textures when the annealing temperatures are 830,850 , and $870^{\circ} \mathrm{C}$, respectively. The intensity of the $\gamma$ fiber texture $(\{111\}<112>)$ first increases and then subsequently reduces with the increase in the annealing temperature. When the annealing temperature is $850^{\circ} \mathrm{C}$, the intensity of the $\{111\}$ surface texture of experimental steel rise up to the maximum.

3. The effect of the second-phase particles on recrystallization texture is mainly determined by the size, the number and the distribution of the particles. Fine and dispersive second-phase particles have a strong pinning force on grain boundaries, which significantly hinder the development of $\{111\}$ surface textures. The weak pinning force of coarse and sparse second-phase particles on grain boundaries promote the development of $\{111\}$ texture. 
Acknowledgments. The authors are very thankful for financial support from the Natural Science Foundation of China (NSFC: No. 51474127. Influence of the size effect on the deformation behavior of profile and flexible rolling at the micro scale and No. 51671100. Preparation of composite micro drill material and micro extrusion forming mechanism) and the State Key Laboratory of Metal Material for Marine Equipment and Application-School of Material and Metallurgy, University of Science and Technology Liaoning co-project (No. SKLMEA-USTLN 2017010).

1. L. Wang, X. F Yang, and J. X. Lu, "Development of high strength steel sheets for lightweight automobile," Iron Steel, 41, No. 9, 1-8 (2006).

2. Y. Hosoya, T. Urabe, K. Tahara, et al., "Super formable steel sheet with tensile strength of 390-440 N/mm²," NKK Tech. Rev., No. 72, 1-9 (1995).

3. S. K. Tiwary, C. N. Jha, A. J. Khan, et al., "Development of interstitial free steel at Tata steel," Trans Indian Inst. Met., 54, No. 3, 117-123 (2001).

4. J. Ma, W. M. Gao, and X. Y. Luo, "Analysis and research of second phase particles in cold rolled annealed sheet of IF steel," Gansu Metallurgy, No. 3, 21-26 (2017).

5. J. C. Zhang, H. S. Di, G. W. Jiang, and C. Yu, "Effect of annealing temperature on FeTiP-type precipitate in P-Added IF high strength steel," J. Northeastern Univ., No. 35, 1404-1410 (2014).

6. Y. J. Li, Research of Relationship between Cold-Rolled Process Parameters and Deep Drawing Performance of IF Steel, Hebei University of Technology, Tangshan (2002).

7. T. Urabe, F. Kitano, T. Fujita, et al., "State-of-art high strength steel sheet for the automotive application," Mater. Sci. Forum, 539-543, 4369-4374 (2007).

8. Z. D. Wang, Y. H. Guo, D. Q. Sun, et al., "Texture comparison of an ordinary IF steel and a high-strength IF steel under ferritic rolling and high-temperature coiling," Mater. Charact., 57, Nos. 4-5, 402-407 (2006).

9. I. L. Dillamore and W. T. Roberts, "Rolling textures in f.c.c. and b.c.c. metals," Acta Metall. Mater., 12, No. 3, 281-293 (1964).

10. P. Jia, "Study on development and production technology of IF steel," Gansu Metallurgy, No. 3, 39-42 (2017).

11. F. Y. Yu, Y. N. Wang, and Q. W. Jiang, "The research of deep drawing IF steel recrystallization $\{111\}$ fiber texture's formation mechanism," Int. J. Mater. Sci. Technol., 16, No. 5, 30-35 (2006).

12. H. W. Yen, P. Y. Chen, C. Y. Huang, and J. R. Yang, "Interphase precipitation of nanometer-sized carbides in a titanium-molybdenum-bearing low-carbon steel," Acta Mater., 59, No. 16, 6264-6274 (2011).

13. S. Matsuoka, K. Hasegawa, and Y. Tanaka, "Newly-developed ultra-high tensile strength steels with excellent formability and weldability," JFE Tech. Rep., No. 10, 13-20 (2007).

14. T. Urabe and J. J. Jonas, "Modeling texture change during the recrystallization of an IF steel," ISIJ Int., 34, No. 5, 435-442 (1994).

15. Q. W. Jiang, E. B. Zhao, J. G. Zhang, et al., "Texture, microstructure and secondphase particles in a Ti+P interstitial free (IF) steel," Mater. Sci. Forum, 495-497, 423-428 (2005).

16. S. Tangen, K. Sjølstad, T. Furu, and E. Nes, "Effect of concurrent precipitation on recrystallization and evolution of the P-Texture component in a commercial Al-Mn alloy," Metall. Mater. Trans. A, 41, No. 11, 2970-2983 (2010). 
17. C. Y. Huang, H. W. Yen, Y. T. Pan, and J. R. Yang, "The development of nano-precipitation strengthened hot-rolled automobile steels," Int. J. Min. Metall., 53, 45-60 (2010).

18. H. W. Yen, C. Y. Chen, T. Y. Wang, et al., "Orientation relationship transition of nanometre sized interphase precipitated TiC carbides in Ti bearing steel," Mater. Sci. Tech., 26, No. 4, 421-430 (2010).

19. Z. C. Wang, X. J. Wang,and X. G. Zhu, "The character feature of interstitial free high strength steel," Iron Steel, 30, No. 2, 63-68 (1995).

20. Z. S. Zhao, W. M. Mao, and Y. N. Yu, "The effect of Ti on the second-phase particles precipitation and mechanical properties for high strength steel," Iron Steel, 35, No. 9, 47-51 (2000).

21. R. Song, D. Ponge, D. Raabe, and R. Kaspar, "Microstructure and crystallographic texture of an ultrafine grained $\mathrm{C}-\mathrm{Mn}$ steel and their evolution during warm deformation and annealing," Acta Mater., 53, No. 3, 845-858 (2005).

22. A. Merlini and P. A. Beck, "Study of the origin of the cube texture," Acta Metall. Mater., 1, No. 6, 598-606 (1953).

23. J. Shi and X. Wang, "Comparison of precipitate behaviors in ultra-low carbon, titanium-stabilized interstitial free steel sheets under different annealing processes," $J$. Mater. Eng. Perform., 8, No. 6, 641-648 (1999).

24. P. Ghosh, C. Ghosh, and R. K. Ray, "Precipitation in interstitial free high strength steels," ISIJ Int., 49, No. 7, 1080-1086 (2009).

25. P. Ghosh, C. Ghosh, R. K. Ray, and B. Bhattacharaya, "Precipitation behavior and texture formation at different stages of processing in an interstitial free high strength steel," Scripta Mater., 59, No. 3, 276-278 (2008).

Received ??. ??. 2019 